\title{
In-vivo myometrial electrical activity in the cyclic mare
}

\author{
M. A. M. Taverne, G. C. van der Weyden, P. Fontijne, S. J. Dieleman, \\ R. L. Pashen* and W. R. Allen*
}

Clinic for Veterinary Obstetrics, A.I. and Reproduction, State University of Utrecht, The Netherlands and *A.R.C. Institute of Animal Physiology, Animal Research Station, Cambridge CB3 OJQ, U.K.

\begin{abstract}
Summary. Uterine electromyography was performed by means of chronically implanted surface electrodes in 3 Pony mares during spontaneous oestrous cycles and following luteolysis induced by a prostaglandin analogue (fluprostenol). Three distinct patterns were recognized during the oestrous cycle. (1) During oestrus well defined phases of activity with closely grouped high-amplitude spikes were separated by long periods (10-45 min) of complete inactivity. (2) During dioestrus more diffuse phases of activity with low-amplitude spikes were separated by variable periods of relative inactivity. (3) During luteolysis, short and frequently occurring phases of activity were propagated between the two electrodes on one uterine horn; a similar pattern also occurred between 1 and $3 \mathrm{~h}$ after injection of fluprostenol. Peripheral plasma progesterone, but not total unconjugated oestrogen, concentrations were closely related to characteristics of the myographic activity during the cycle.

Insemination during oestrus and injection of fluprostenol during dioestrus caused a marked and prolonged increase in myometrial electrical activity. Almost any non-specific environmental stimulus, including entry to the mare's stall and the sound of human voices, was able to influence myometrial activity at any stage of the cycle. Similar changes in activity were induced by palpation of the genital tract per rectum and vaginoscopic examination, but these were of brief duration and the normal resting pattern of activity was quickly re-established after completion of the manipulations.
\end{abstract}

\section{Introduction}

Measurements of myometrial electrical activity and intrauterine pressure changes in the cow (Zerobin \& Spörri, 1972; Ruckebusch \& Bayard, 1975; Brand et al., 1976), sheep (Naaktgeboren et al., 1973; Rousseau \& Prud'homme, 1974; Ruckebusch \& Bueno, 1976) and pig (Zerobin \& Spörri, 1972) have demonstrated distinct patterns of uterine contractions during the oestrous cycle; in all these species, myometrial activity was greatest around oestrus and at a minimum in mid-dioestrus. Similar studies have not been reported for the horse despite the concern expressed by Voss \& Pickett (1975), Osborne (1975) and others that the gynaecological examinations routinely practised in equine veterinary stud management may lower fertility by stimulating harmful contractions in the genital tract of mares. This paper describes the pattern of myometrial electrical activity of the mare throughout the oestrous cycle and examines the influence of physical and pharmacological stimulation of the genital tract on this activity.

\section{Materials and Methods}

The experiments were performed between April and October on one Shetland Pony aged 7 years and two Welsh Mountain Pony mares aged 3 and 4 years. The uterus of each mare was exposed via a mid-ventral laparotomy incision performed under general anaesthesia and four pairs of 
small silver electrodes were implanted into the myometrium as described by Naaktgeboren et al. (1973); one pair of electrodes was placed near the bifurcation (Electrodes 2 and 4) and another towards the tubal end (Electrodes 1 and 3) of each uterine horn. The wires from each electrode were passed through the abdominal musculature in the left flank and then tracked subcutaneously to the middle of the back where they were connected to a plug sutured to the skin.

For recording of myometrial activity, the plug was connected via a long cable to the recording equipment (time constant of pre-amplifiers: $0.03 \mathrm{sec}$ ) situated in an adjacent room and for which details have been described by Naaktgeboren et al. (1973). A four-channel Minograf 81 model recorder (Elema-Schonander Ltd, Sweden) running with a constant speed of 2.5 $\mathrm{mm} / \mathrm{min}$ was used and 3 of the 4 channels could be registered simultaneously on a Cardiostat-3T Model recorder (Siemens, Erlangen, Germany) with a much slower paper speed of $1 \mathrm{~cm} / \mathrm{min}$. Each recording session lasted at least $2 \mathrm{~h}$ and during this time the mares were placed in individual stalls equipped with closed-circuit television to allow observation of behaviour.

One jugular vein of each mare was cannulated to allow regular blood sampling with minimal disturbance of the animal. Samples were centrifuged immediately after collection and the plasma was stored at $-20^{\circ} \mathrm{C}$ until assay for progesterone and oestrogen concentrations. Progesterone was assayed by the radioimmunoassay described by de Jong, Baird \& van der Molen (1974) using an antiserum raised in a rabbit against an $11 \alpha$-hydroxyprogesterone-hemisuccinate-BSA conjugate which exhibited cross-reactions of $100 \%$ with progesterone, $17 \%$ with $11 \beta$-hydroxyprogesterone, $16.5 \%$ with $5 \alpha$-pregnane-3,20-dione, $3.9 \%$ with $16 \alpha$-hydroxyprogesterone and $2.2 \%$ with $17 \alpha$-hydroxyprogesterone. Duplicate $1 \mathrm{ml}$ aliquots of plasma were extracted with redistilled n-hexane (Merck A.G., Darmstadt, West Germany) before assay, $\left[1,2,6,7(\mathrm{n}){ }^{3} \mathrm{H}\right]$ progesterone (sp. act. $84 \mathrm{Ci} / \mathrm{mmol}$; Radiochemical Centre, Amersham, U.K.) was used as tracer and free and antibody-bound progesterone were separated with dextran-coated charcoal. Intra- and inter-assay coefficients of variation were 11 and $12.2 \%$ respectively. Total unconjugated oestrogen concentrations were measured by radioimmunoassay as described by Moor, Hay, McIntosh \& Caldwell (1973) using an antiserum prepared in a goat against a 17 $\beta$-oestradiolhemisuccinate-BSA conjugate (Furr 461/6) which exhibited cross-reactions of $100 \%$ with oestradiol- $17 \beta, 53 \%$ with oestrone, $17 \%$ with equilin- $17 \beta, 14 \%$ with equilin, $9 \%$ with equilenin, $4 \%$ with equilenin- $17 \beta$ and $0.5 \%$ with androstenedione. Duplicate $1 \mathrm{ml}$ aliquots of plasma were extracted with re-distilled petroleum ether (b.p. $40-60^{\circ} \mathrm{C}$ : Fisons, Loughborough, U.K.) before assay, $\left[6,7-{ }^{3} \mathrm{H}\right]$ oestradiol (sp. act. $41 \mathrm{Ci} / \mathrm{mmol}$; Radiochemical Centre, Amersham, U.K.) was used as tracer and free and antibody-bound oestrogen were separated on small G-25 Sephadex columns. Intra- and inter-assay coefficients of variation were 7 and $16 \%$ respectively.

Analysis of the myometrial electrical activity recordings was concentrated on the patterns, the duration and frequency of the active phases, and the maximal amplitude of the spikes. Regular recordings were made at defined stages throughout one or more oestrous cycles in all three mares. In addition, the effects of various environmental stimuli and clinical manipulations, such as rectal palpation of the uterus, vaginoscopic examination, artificial insemination and treatment with an analogue of prostaglandin (PG) F-2 $\alpha$, on uterine activity were examined.

\section{Results}

\section{Reproductive patterns of the mares}

The pre- and post-surgical sexual cycles exhibited by the 3 mares may be summarized as follows.

Shetland Pony, SH showed no oestrous behaviour during the 60 days before surgery, no follicular development at surgery and plasma progesterone levels of 5-9 $\mathrm{ng} / \mathrm{ml}$ between Days 8 and 25 after surgery. Normal oestrous behaviour occurred from Days 29 to 36 after surgery and ovulation was diagnosed by rectal palpation on Day 35. Recordings continued until Day 7 of dioestrus. 
Welsh Pony, DC. Two regular oestrous cycles were exhibited before surgery as judged by teasing behaviour, rectal palpation of the ovaries and serial plasma progesterone measurements. After surgery during mid-dioestrus, there was one complete oestrous cycle but the second cycle was shortened by i.m. injection of $250 \mu \mathrm{g}$ fluprostenol (Equimate: ICI Pharmaceuticals Ltd, Cheshire, U.K.), a PGF-2 $\alpha$ analogue, on Days 11 and 12 of dioestrus. A 'split oestrus' of 11 days duration commenced 1 day after the second injection of fluprostenol. Recordings and blood sampling continued for the next 2 cycles which were normal.

Welsh Pony, $R B$ had 5 regular oestrous cycles before surgery at mid-dioestrus. Surgery was followed by a period ( 21 days) of prolonged dioestrus as judged by elevated progesterone levels $(12-35 \mathrm{ng} / \mathrm{ml})$ and the absence of oestrous behaviour. Injections of $250 \mu \mathrm{g}$ fluprostenol on Days 21 and 22 after surgery caused luteolysis but oestrous behaviour was not observed until 3 days after the second of two s.c. injections of $50 \mu \mathrm{g}$ and $30 \mu \mathrm{g}$ on Days 32 and 35 respectively of a potent synthetic analogue of gonadotrophin-releasing hormone (Hoe 766: Hoeschst Ltd, Frankfurt, West Germany). No further oestrous cycles were observed.

\section{Myometrial activity during the oestrous cycle}

Three quite different and distinct patterns of myometrial electrical activity could be recognized from the electromyographs (EMGs) of all 3 mares.

Pattern 1-oestrus. The typical pattern exhibited during spontaneous oestrus and that following PG-induced luteolysis is shown in Text-fig. 1. Phases of high amplitude, densely grouped spikes (duration: $2-8 \cdot 5 \mathrm{~min}, 1 \cdot 6-6 \cdot 7 / \mathrm{h}$, spike amplitude $150-600 \mu \mathrm{V}$ ) alternated with periods $(10-45 \mathrm{~min})$ of complete inactivity. Both uterine horns showed simultaneous activity.

Pattern 2-dioestrus. This pattern is shown in Text-fig. 2. Diffuse phases of low amplitude spikes (duration: $15-20 \mathrm{~min}, 1 \cdot 5-4 \cdot 5 / \mathrm{h}$, spike amplitude $50-200 \mu \mathrm{V}$ ) alternated with periods of relative inactivity during which small bursts of spikes $(1-3 \mathrm{sec})$ were prominent.

Pattern 3-luteolysis. Frequent phases of high amplitude, low density spikes (duration: 1-4 min, $7 \cdot 5-17 / \mathrm{h}$, spike amplitude $130-600 \mu \mathrm{V}$ ) alternated with short periods $(1-4 \mathrm{~min})$ of inactivity during spontaneous luteolysis (Text-fig. 3). The pattern was very similar to that registered $1-3 \mathrm{~h}$ after the second of 2 injections of $250 \mu \mathrm{g}$ fluprostenol given to induce luteolysis during dioestrus (Text-fig. 4). Propagation of the active phases from one set of electrodes to the other was obvious in this pattern and differences in frequency and duration of the phases between the left and right horns were also detected.

Both the occurrence and maximal amplitude of the spikes of the three different patterns of myometrial activity appeared to be closely correlated with peripheral plasma progesterone concentrations (Text-fig. 8). No such correlation was apparent for plasma oestrogen concentrations, however, which fluctuated widely throughout the cycle.

\section{Influence of environmental stimuli}

Non-specific environmental stimuli, such as entry to the mare's stall, feeding, and even the sound of human voices in an adjoining room (Text-fig. 6), induced temporary but marked changes in myometrial activity at all stages of the oestrous cycle. Similarly, presentation of a stallion to the mare during oestrus and dioestrus induced a short period of increased activity which subsided again within a few minutes after removal of the stallion.

\section{Effect of gynaecological examination}

On all but 1 of 11 occasions when rectal examination of the ovaries and uterus was carried out during oestrus or dioestrus, myometrial electrical activity had already begun as a result of the palpator entering the mare's stall and preparing to undertake the examination (Text-fig. 6). Activity continued during palpation but lasted for only a few minutes after it was completed and 


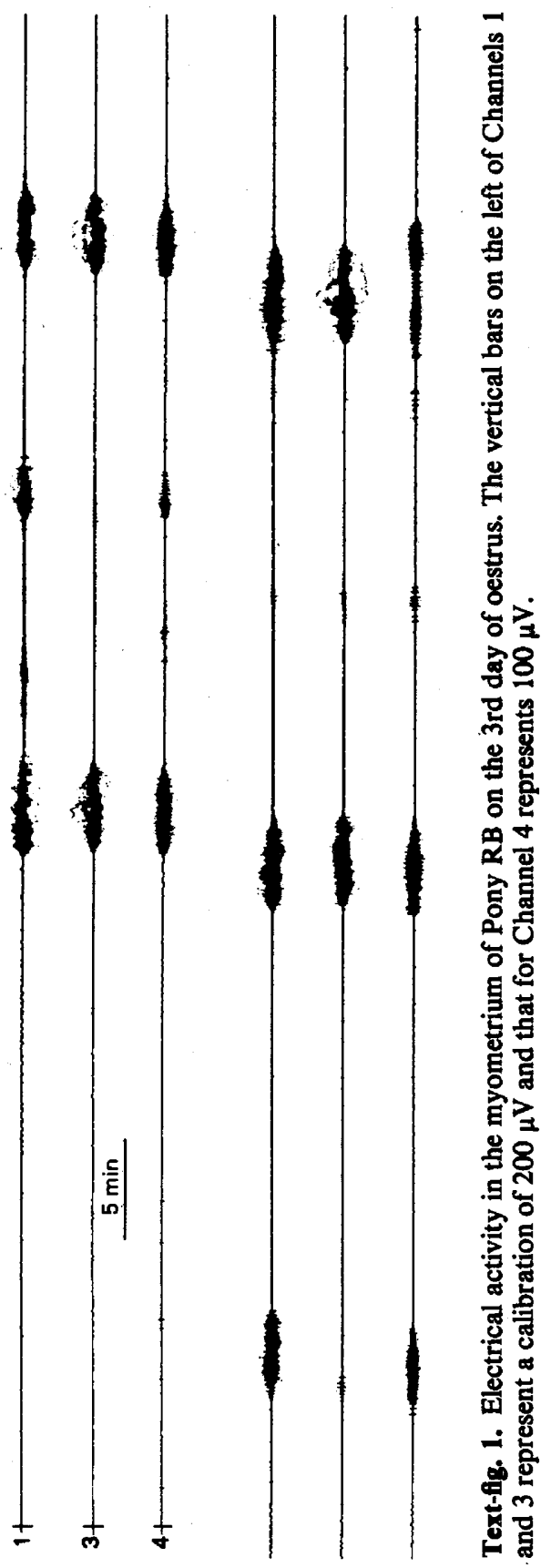




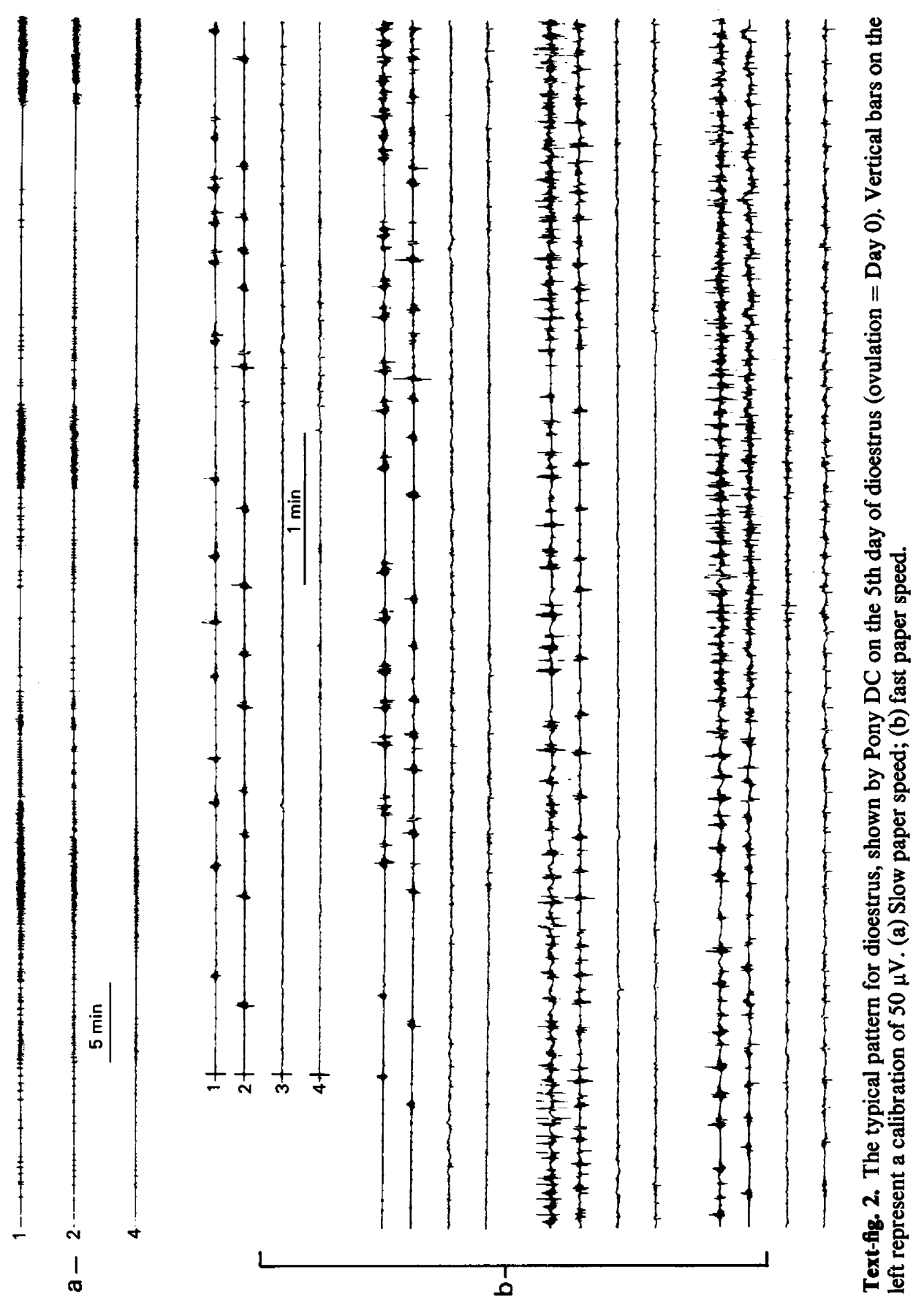




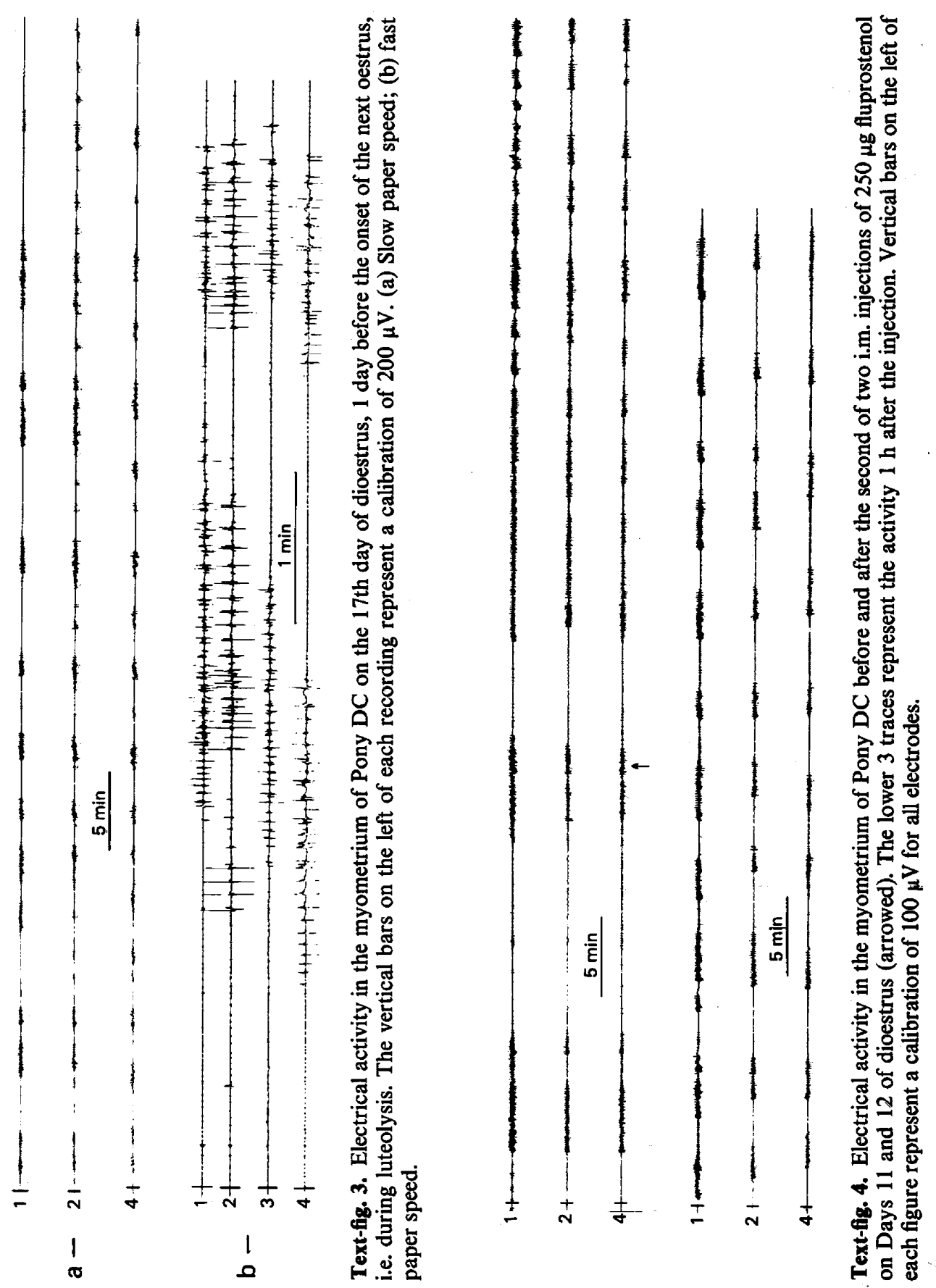




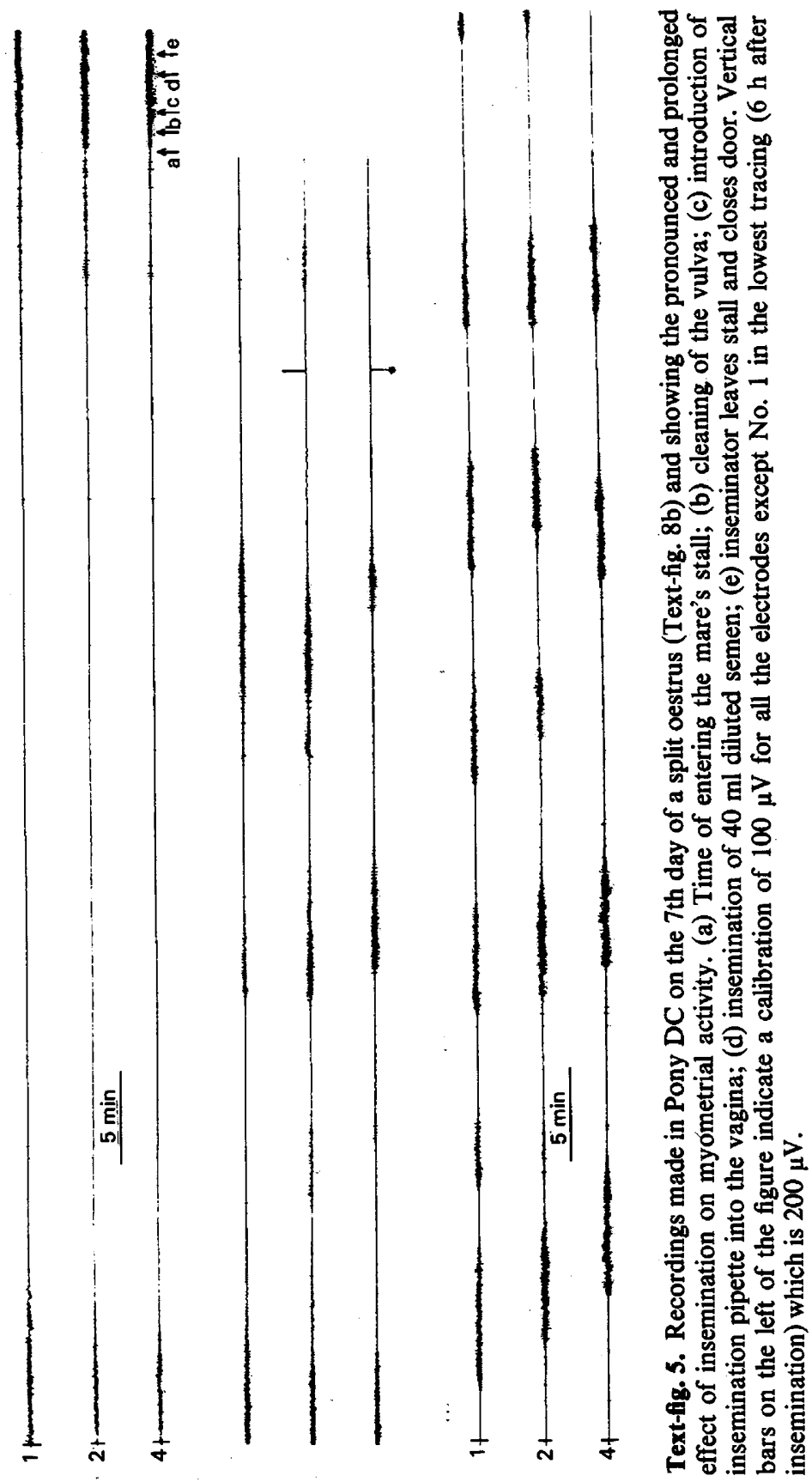




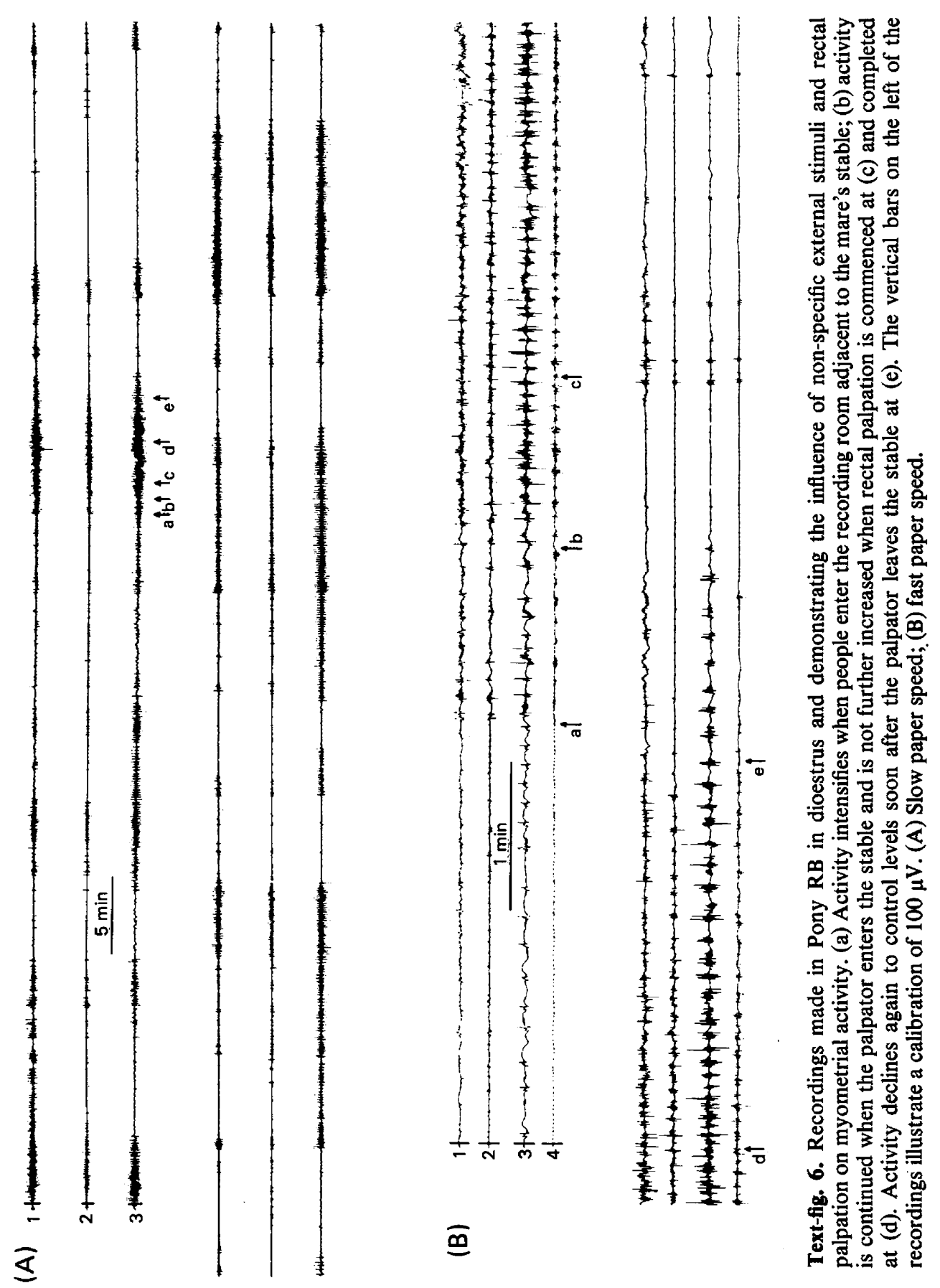




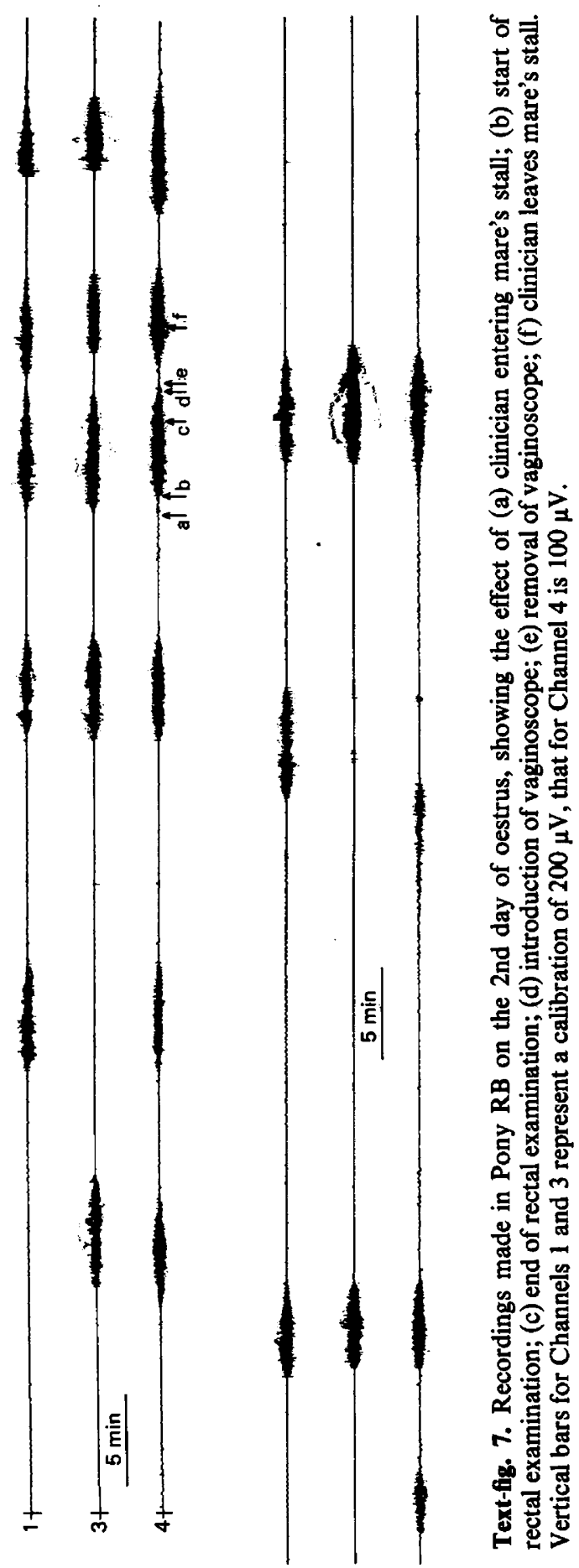



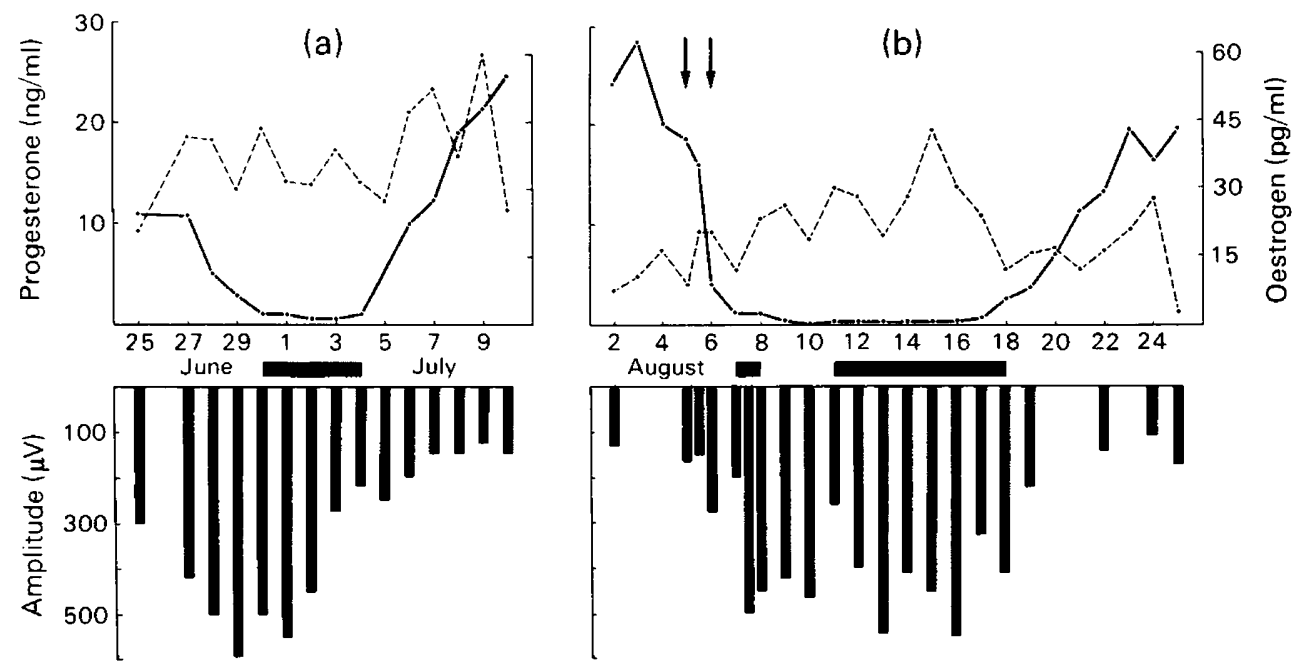

Text-fig. 8. Progesterone (-) and total unconjugated oestrogen (---) concentrations in the peripheral plasma of Pony DC during (a) a normal oestrous cycle and (b) oestrus induced by two i.m. injections of $250 \mu \mathrm{g}$ fluprostenol on consecutive days (arrows). The vertical bars represent the maximum amplitudes measured by one pair of electrodes situated at the anterior end of the left uterine horn during recordings of myometrial activity. The horizontal bars represent oestrus.

no significant changes in the pattern of the EMGs occurred afterwards. On three occasions when rectal palpation was followed immediately by distension of the vagina with a cylindrical speculum, the uterine activity seen during rectal palpation was either prolonged or a new phase of activity was induced which was relatively short-lived (Text-fig. 7). The amplitudes of the spikes registered during the examination did not differ significantly from those occurring beforehand.

\section{Effect of artificial insemination}

Four intrauterine inseminations with $10-40 \mathrm{ml}$ fresh or diluted stallion semen were carried out in the Pony DC, three times during the second part of her split oestrus and once during the next oestrus. At the time of insemination myometrial activity was similar to that observed during rectal palpation. After 3 of the inseminations, however, the activity increased markedly, with spikes of higher amplitude and more frequent active phases persisting for $2-7 \mathrm{~h}$ (Text-fig. 5).

\section{Effect of prostaglandin}

The two Welsh Pony mares were each injected with $250 \mu \mathrm{g}$ fluprostenol when their plasma progesterone levels were (DC) 18.9 and (RB) $12.5 \mathrm{ng} / \mathrm{ml}$. All electrodes showed continuous electrical activity for 20-30 min after the injection although the amplitudes of the spikes did not change. Thereafter the EMG returned to the pre-injection pattern in DC, while in RB the continuous activity was gradually interrupted by increasing periods of inactivity.

By $24 \mathrm{~h}$ after the first injection of fluprostenol, plasma progesterone levels had declined to (DC) 4.3 and (RB) $1.9 \mathrm{ng} / \mathrm{ml}$. Pony DC then showed an EMG pattern intermediate between those described for dioestrus and oestrus while Pony RB exhibited a typical oestrous pattern. Following a second injection at this time, the EMGs of both mares once again showed continuous activity for 15-30 min. This was gradually interrupted by brief periods of inactivity (Text-fig. 4) which steadily lengthened and the typical pattern found during spontaneous luteolysis was present by $1-2 \mathrm{~h}$ (see Text-figs 3 and 4 ). 


\section{Discussion}

Uterine electrical activity, as measured by extracellular electrodes, is usually related to myometrial contractions and intrauterine pressure changes (Csapo, Takeda \& Wood, 1963; Rousseau \& Prud'homme, 1974). However, exceptions have been reported (Wolfs, van Leeuwen, Rottinghuis \& Boeles, 1971; Zerobin \& Spörri, 1972; Rousseau \& Prud'homme, 1974) and for this reason we use the description "phases of uterine electrical activity" rather than "uterine contractions".

The influence of the stage of the oestrous cycle on myometrial activity in the mare appears to be different from that observed in other large domestic animals. The extended periods of complete electrical inactivity (10-45 $\mathrm{min}$ ) separated by phases of high amplitude activity during oestrus differ markedly from the very frequent and intense phases of electrical activity observed around oestrus in the sheep (Naaktgeboren et al., 1973; Rousseau \& Prud'homme, 1974; Ruckebusch \& Bueno, 1976) and cow (Ruckebusch \& Bayard, 1975; Brand et al., 1976). Similarly, the diffuse but definite phases of low amplitude electrical activity which occur throughout dioestrus in the mare are in sharp contrast to the almost total absence of myometrial activity observed during dioestrus in the cow (Brand et al., 1976) and sheep (Naaktgeboren et al., 1973). A further contrast exists during luteolysis when the uterine inactivity of dioestrus persists in the sheep and cow whereas myometrial activity is at its greatest in the mare with high frequency phases of electrical discharges. This may be related to the more prolonged release of PGF- $2 \alpha$ which occurs in mares than in ewes or cows during spontaneous luteolysis (Kindahl et al., 1976; Neely, Kindahl, Stabenfeldt, Edqvist \& Hughes, 1979).

While changes in the EMG occurring around oestrus can be related to increased ovarian oestrogen production in the cow (Brand et al., 1976), pig (Zerobin \& Spörri, 1972) and sheep (Rousseau \& Prud'homme, 1974), the changes in the uterine EMGs in the cyclic mare did not show any obvious relationship to circulating oestrogen concentrations which fluctuate widely throughout the cycle with a variable and ill-defined peak at mid-oestrus. However, the pattern and amplitude of the electrical activity did appear to be closely associated with the presence or absence of progesterone in the blood in the mare (Text-fig. 1), as reported by Csapo \& Takeda (1965) for the pregnant rabbit.

Fluprostenol had a marked influence on myometrial activity in mares, regardless of plasma progesterone concentrations. The potent smooth muscle-stimulating activity of this particular compound has already been demonstrated in women by Csapo \& Mocsary (1976) and this property is likely to be the underlying cause of the very rapid parturition (30-90 min) which occurs after a single injection of $250 \mu \mathrm{g}$ fluprostenol to mares at term (Rossdale, Jeffcott \& Allen, 1976).

The prolonged increase in myometrial activity which followed the intrauterine insemination of fresh or egg yolk-diluted semen on 3 occasions was most probably caused by the presence of smooth muscle-stimulating substances in the inseminate. The potent luteolytic action of fresh stallion semen when inseminated into mares in dioestrus (W. Bielański \& M. Tischner, personal communication) would suggest the presence of seminal prostaglandins, but the simple stretching effect caused by the volume of the inseminate or an inflammatory influence of the semen might also contribute to the increased uterine activity.

A striking finding in our study was the pronounced reactivity of the mare's myometrium to environmental stimulation; temporary disturbances of the normal resting pattern occurred irrespective of the stage of the oestrous cycle. Although non-specific environmental stimuli may affect uterine electrical activity in the non-pregnant rabbit (Ruckebusch, 1975), the pregnant rabbit and sheep (Bontekoe, Blacquiere, Naaktgeboren, Dieleman \& Willems, 1977) and the cyclic sheep and sow (G. C. van der Weyden \& M. A. M. Taverne, unpublished data), the mare seems to be far more sensitive in this respect. By contrast, it was surprising to find that rectal palpation of the uterus had little effect upon myometrial activity. Brand et al. (1976) reported 
similar findings of rectal palpation in the cow and were unable to demonstrate any significant effects on myometrial activity of prolonged manipulation of the genital tract during sham nonsurgical recovery and transfer of embryos.

Voss \& Pickett (1975) reported a significant prolongation of oestrus and a reduction in conception rate in mares subjected to rectal palpation of the uterus and ovaries during oestrus compared to results for non-palpated mares. However, our results indicate that any harmful effects of rectal palpation which may occur in the mare cannot be attributed to disturbances of the normal patterns of myometrial activity.

We thank Miss D. M. Blankenstein, Mr D. van Bruggen, Mr J. Lubberink, Dr D. Nitschelm and $\mathrm{Dr}$ W. van der Holst for assistance and the care and maintenance of the mares. The project was supported by The Thoroughbred Breeders' Association of Great Britain.

\section{References}

Bontekoe, E.H.M., Blacquiere, J.F., Naaktgeboren, C., Dieleman, S.J. \& Willems, P.P.M. (1977) Influence of environmental disturbances on uterine motility during preganancy and parturition in rabbit and sheep. Behavioural Processes 2, 41-73.

Brand, A., Taverne, M.A.M., van der Weyden, G.C., Aarts, M.H., Dieleman, S.J., Drost, M. \& de Bois, C.H.W. (1976) Myometrial activity as a possible cause of embryo expulsion. In Egg Transfer in Cattle, pp. 44-57. Ed. L. E. A. Rowson. EEC, Luxembourg.

Csapo, A.l. \& Mocsary, P. (1976) Menstrual induction with PGF $2 \alpha$ analogue (ICI 81008). Prostaglandins $11,155-158$.

Csapo, A.L. \& Takeda, H. (1965) Effect of progesterone on the electrical activity and intrauterine pressure of pregnant and parturient rabbits. Am. J. Obstet. Gynec. 91, 221-231.

Csapo, A.J., Takeda, H. \& Wood, C. (1963) Volume and activity of the parturient rabbit uterus. Am.J. Obstet. Gynec. 85, 813-818.

de Jong, F.H., Baird, D.T. \& van der Molen, H.J. (1974) Ovarian secretion rates of oestrogens, androgens and progesterone in normal women and in women with persistent ovarian follicles. Acta endocr., Copenh. 77, 575-587.

Kindahl, H., Granstrom, E., Edqvist, L.E., Neely, D., Hughes, J.P. \& Stabenfeldt, G.H. (1976) The advantages of measuring a prostaglandin $F 2 \alpha$ metabolite in peripheral blood in studies of the physiological role of prostaglandin release during luteolysis in domestic animals. Proc. 8th Int. Congr. Anim. Reprod. \& A.I., Krakow, Vol. II, pp. 145-148.

Moor, R.M., Hay, M.F., McIntosh, J.E.A. \& Caldwell, B.V. (1973) Effect of gonadotrophins on the production of steroids by sheep ovarian follicles in vitro. $J$. Endocr. 58, 599-611.

Naaktgeboren, C., van der Weyden, G.C., Klopper, P.J.,
Kroon, C.H., Schoof, A.G. \& Taverne, M.A.M. (1973) Electrophysiological observations of uterine motility during the oestrous cycle in sheep. $J$. Reprod. Fert. 35, 511-518.

Neely, D.P., Kindahl, H., Stabenfeldt, G.H., Edqvist, L.E. \& Hughes, J.P. (1979) Prostaglandin release patterns in the mare; physiological, pathophysiological and therapeutic responses. J. Reprod. Fert., Suppl. 27, 181-189.

Osborne, V.E. (1975) Factors influencing foaling percentages in Australian mares. J. Reprod. Fert., Suppl. 23, 477-483.

Rossdale, P.D., Jeffeott, L.B. \& Allen, W.R. (1976) Foaling induced by a synthetic prostaglandin analogue (Fluprostenol). Vet. Rec. 99, 26-28.

Rousseau, J.P. \& Prud'homme, M.J. (1974). Etude electromyographique de la motricite de l'uterus chez la brebis. Action des hormones. Annls Biol. anim. Biochim. Biophys. 14, 67-85.

Ruckebusch, Y. (1975) Relationship between the electrical activity of the oviduct and the uterus of the rabbit in vivo. J. Reprod. Fert. 45, 73-82.

Ruckebusch, Y. \& Bayard, F. (1975) Motility of the oviduct and uterus of the cow during the oestrous cycle. J. Reprod. Fert. 43, 23-32.

Ruckebusch, Y. \& Bueno, L. (1976) An electromyographic study of uterotubal activity in the ewe. $J$. Reprod. Fert. 47, 221-227.

Voss, J.L. \& Pickett, B.W. (1975) The effect of rectal palpation on the fertility of cyclic mares. J. Reprod. Fert., Suppl. 23, 285-290.

Wolfs, G., van Leeuwen, M., Rottinghuis, H. \& Boeles, J.Th. (1971) An electromyographic study of the human uterus during labor. Obstet. Gynec., N.Y. 37, 241-246.

Zerobin, K. \& Spörri, H. (1972) Motility of the bovine and porcine uterus and fallopian tube. Adv, vet. Sci. comp. Med. 16, 303-354.

Received 27 September 1978 